\title{
Deneysel osteomiyelit modellerine güncel yaklaşım
}

\section{Current approach to experimental osteomyelitis models}

\author{
Fehmi Volkan Öztuna ${ }^{1,2}$, Ender Gümüşoğlu ${ }^{1}$ \\ ${ }^{1}$ Mersin Üniversitesi Tıp Fakültesi Hastanesi, Ortopedi ve Travmatoloji Anabilim Dalı, Mersin \\ ${ }^{2}$ VM Medical Park Mersin Hastanesi, Mersin
}

\begin{abstract}
Tedavi hedeflerini belirlemek, yeni aşıları ve antimikrobiyal ajanları test etmek, biyofilm oluşması ve kemik yıkımı gibi sorunlu faktörleri tanımlamak için çok sayıda deneysel osteomiyelit modeli geliştirilmiştir. Tarihsel olarak, osteomiyelitin hayvan modelleri; radyografi, histoloji, klinik skorlama sistemleri ve patojen yükünün yarı kantitatif ölçümleri gibi ölçümlere dayanmaktadır. Bu yazıda nicel bakteriyolojik ve görüntüleme araçlarına, biyofilm oluşmasının modellenmesine ve lokal antimikrobiyal uygulama stratejilerine odaklanarak osteomiyelitin in vivo ve in vitro deney modellerinde yeni gelişmeleri gözden geçirdik.
\end{abstract}

Anahtar sözcükler: deneysel; osteomiyelit; in vivo, in vitro
Numerous experimental osteomyelitis models have been developed to set therapeutic targets, test new vaccines and antimicrobial compounds, and identify factors limiting model therapy such as biofilm formation and bone destruction. Historically, animal models of osteomyelitis; based on assisted pathogenesis measurements such as radiography, histology, clinical scoring systems, and semi-quantitative measurements of pathogen burden. We highlight new developments in experimental models of osteomyelitis, with a focus on quantitative bacteriologic and imaging tools, modeling of biofilm growth and strategies for local antimicrobial delivery.

Key words: experimental; osteomyelitis; in vivo, in vitro

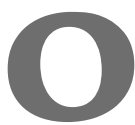

steomiyelitin gelişim sürecinde, kişinin bağışıklık sistemi ve mikroorganizmanın virülansı ile ilgili birçok faktör rol oynadığı için henüz osteomiyelitin patogenezi konusunda fikir birliğine varılamamıştır. İnsanlarda, hastalığın ne zaman başladığını bilme ve kişisel değişkenlere müdahale etme şansı olmadığı için kontrollü klinik çalışmalar yapmak olası değildir. Bu nedenle tedavi amaçlı yaklaşımları, iyi tanımlanmış hayvan modellerini kullanarak deneysel ortamlara taşımak gerekir. Hayvan deneylerinin, antibiyotiklerin kemik dokudaki seviyesini ya da serum bakterisidal seviyesini monitörize edebilme gibi avantajları da vardır. Bu durumda hayvan deneyleri, osteomiyelit patogenezi ve tedavisinin incelenebildiği en güvenilir yöntemler olarak karşımıza çıkmaktadır.

Antibiyotiklerin, enfeksiyonları tedavi etmekte yetersiz kaldığı bu günlerde, S.aureus enfeksiyonlarının en etkili tedavisi kuşkusuz bir şekilde aşılama ile bağışıkıı kazandırmaktır. Fakat günümüzde yapılan aşı çalışmalarının (V710) geldiği son noktada, istenmeyen ölümler dahil olmak üzere ciddi komplikasyonlar görülmektedir ve henüz bir başarı elde edilememiştir. Bu nedenle halen osteomiyelit tedavisinde yeni tasarımlar belirlemek, yeni aşıları ve antimikrobiyal ajanları test etmek, biyofilm oluşumu ve kemik yıkımı gibi sorunları tanımlamak için çok sayıda deneysel (in vitro ve in vivo) osteomiyelit modeli geliştirilmektedir.

\section{IN VITRO OSTEOMIYELIT MODELLERI}

Enfeksiyon sürecinde osteomiyelitin erken (klinik olarak belirgin olmayan) evrelerinin incelenmesi zordur ve hatta mümkün değildir. Bu nedenle, erken hastalık aşamalarında osteomiyelitin insan kemik iliği ve hematopoez üzerindeki etkisini araştırmak için in vitro model sistemlerine ihtiyaç vardır Ayrıca, hayvan modellerinin kısıtlamaları vardır: i) Osteomiyelitin ana nedeni biyofilm olmasına rağmen, halen birçok deneysel modelde intramedüller alana bakteri inokülasyonu yapılmaktadır; ii) hayvan modellerinde osteomiyelit gelişme oranları tutarsızdır (\%47-100) ve iii) enfekte hayvanların ölüm oranı yüksektir ${ }^{[1,2]}$; iv) günümüze kadar yapılan in vitro çalışmalar, insan

- Iletişim adresi: Prof. Dr. Fehmi Volkan Öztuna, VM Medical Park Mersin Hastanesi, Mersin

Tel: 0532 - 4312257 e-posta: oztuna67@hotmail.com

- Geliș tarihi: 26 Mayıs $2020 \quad$ Kabul tarihi: 23 Haziran 2020 
hücrelerinin bakteriyel membran bileşenlerine, salınan bakteriyel faktörlere veya bakterilere yanıtının araştırıldığı geleneksel iki boyutlu hücre kültürleriyle sınırlandırılmıştır. ${ }^{[3-8]}$ Bir yenilik olarak Raic ve ark., ameliyat sonrası osteomiyeliti taklit etmek için biyomimetik kemik/kemik iliği analoğu, kontamine implanttan biyofilm üretebilecek üç boyutlu modeli ve hem bakteriler hem de ökaryot hücreler için gereken uygun büyüme koşullarını ortaya koymuşlardır. Bunu yaparken geleneksel sığır albüminini katyonize ederek oluşturdukları katyonize domuz albümini (cBSA), hücre adhezyon materyal iskelesi olarak kullanmışlardır. Bu modelde osteomiyelite verilen yanıt anlamında hematopoezi incelemenin fonksiyonel ve uygun olduğunu bildirmişlerdir. ${ }^{[9]}$

Tuchscherr ve ark., in vivo ve in vitro osteomiyelit modellerinde S.aureus'un, kronik osteomiyelit sırasında dinamik küçük koloni varyantları oluşturarak antibiyotiklere karşı artan direnç geliştirdiklerini göstermişlerdir. Bu araştırmada in vitro model, hücre kültürlerinde insan osteoblastlarını S.aureus ile enfekte edilerek yapılmıştır. ${ }^{[10]}$

Junka ve ark., in vivo ve eks vivo ortamda oluşturulan biyofilmin konak immunitesi ve osteoklastogenezisten bağımsız olarak kemik destrüksiyonu yaptığını gösterdikleri çalışmada S.aureus, P.aeruginosa, C.albicans ve S.mutans patojenlerini kullanmışlardır. Hidroksiapatit ve rat mandibulası kullanılarak yürütülen bu çalışmada biyofilm tabakasının kemiğe olan direkt etkileri mikro bilgisayarlı tomografi ile ortaya koyulmuştur. In vitro ortamda üretilen biyofilm tabakası ise önce inkübasyon ardından kantitatif kültürler hazırlanmış olup elektron mikroskobisi ile doğrulanmıştır. ${ }^{[11]}$

\section{iN VIVO MODELLER}

Bilinen en eski deneysel osteomiyelit modeli ise 1884 'de Rodet tarafından tavşanlarda yapılmış ve S.aureus'un i.v. olarak verilmesi sonrası kemikte abselerin oluştuğu gözlenmiştir. ${ }^{[12]}$
Günümüzde küçük hayvanlar, osteomiyelit araştırmalarında başarı ile kullanılmaktadır; ancak birden fazla prosedürün yapılamaması ve büyük hayvanlar için kullanılan implantların kullanılamaması dezavantajlarıdır.

Deneysel osteomiyelit modellerine basit bir sınıflama yapılacak olursa:

a) Akut,

b) Kronik;

- İmplantsız enfeksiyonlar

- İmplant ilişkili enfeksiyonlar

olarak sınıflandırılabildiğini görmekteyiz.

Deney hayvanlarında sadece kemik absesi değil ilerleyici karakterde osteomiyelit oluşturmak için lokal kemik hasarı yapmak şarttır. ${ }^{[12]}$ Bunun için kimyasal ve fiziksel yöntemler kullanılmıştır. En sık kullanılan yöntem, kemiğin metafizer bölgesinde bir delik açıp medüller kanala sklerozan madde enjekte etmektir.[13-16] Lokal hasar oluşturduktan sonra bakterinin verilmesi konusunda farklı uygulamalar vardır:

1. Bakterinin sistemik (i.v.) verilmesi

2. Bakterinin lokal verilmesi

Ayrıca ortamda bir yabancı cisim ya da implant varlığı durumunda gelişen osteomiyelitlerin deneysel modelleri için implant/yabancı cisim ilişkili modeller tanımlanmıştır. Bu modeller iki şekilde sınıflandırılabilir:

a) Önceden kolonize edilmiş implant/yabancı cisim konan modeller ${ }^{[17]}$

b) Steril implant/yabancı cisim konan modeller[18]

Bu tekniklerin birçok modifikasyonu olmakla birlikte en sık kullanılan temel modeller Tablo 1'de verilmiştir.

Bu güne kadar osteomiyelitin patogenezi hakkındaki bilgilerin çoğu tavşan, sıçan, fare, kobay, tavuk, köpek, koyun ve keçi üzerinde yapılan çalışmalardan elde edilmiş ve geliştirilen tedavi yaklaşımları bu modeller

Tablo 1. Temel osteomiyelit hayvan modelleri

\begin{tabular}{lll}
\hline Denek & Yazarlar & Teknik \\
\hline Tavşan & Norden ve Kennedy ${ }^{[13]}$ & $\begin{array}{l}\text { Tibiaya intramedüller \%5'lik sodyum moruat enjeksiyonunu takiben } 10^{8} \text { CFU S.aureus verilmesi. } \\
\text { Bu model önce Scheman ve ark. tarafından 1941'de tanımlanmıştır. }\end{array}$ \\
Sıçan & Zak ve ark. ${ }^{[15]}$ & $\begin{array}{l}\text { Tibiaya intramedüller Na moruat enjeksiyonunu takiben } 10^{5-6} \mathrm{CFU} \text { S.aureus verilmesi ve } \\
\text { bonevaks ile deliğin kapatılması. }\end{array}$ \\
Köpek & Fitzgerald ${ }^{[19]}$ & $\begin{array}{l}\text { Tibia metafizinde } 1 \times 1 \text { defekt yapıp } 10^{9} \mathrm{CFU} \text { S.aureus verilmesi ve sement ile defektin } \\
\text { kapatılması. }\end{array}$
\end{tabular}


üzerinde denenmiştir. ${ }^{[20]}$ Osteomiyelit deneylerinin değerlendirilmesi, radyografi, histoloji, klinik skorlama sistemleri ve patojen yükünün yarı kantitatif ölçümleri gibi ölçümlere dayanmaktadır.

\section{MODELLERDEKI YENILIKLER}

Klasik deneysel modellerde çalışma süresi sonunda enfekte kemik ve implant tamamen çıkartılıp gerekli histolojik, mikrobiyolojik değerlendirmeler yapılır ve o denekler çalışmadan çıkartılır. Eğer çalışma daha uzun bir takip dönemi gerekiyorsa farklı bir grup oluşturulup farklı zaman dilimlerine doğru çalışma uzatılır. Brinkman ve ark., S.aures ve S.epidermidis ile biyofilm oluşturdukları üç adet enfekte K-telini, aynı sıçanın tibiasına yerleştirmişlerdir. İşlemden sonra 4., 5., ve 6. haftalarda telleri teker teker çekerek aynı denekte farkI zaman dilimlerinde enfeksiyonu monitörize etme firsatı yakalamışlardır. Rifampisin tedavisinin etkinliğini aynı denekte farklı zaman dilimlerinde gözleme fırsatı oluşturmuşlardır. ${ }^{[21]}$

Büren ve ark., kırık ilişkili enfeksiyonları inceleyen deneysel çalışmalarda kullanılan histolojik sınıflamanın daha kapsamlı olması gerektiğini savunarak yeni bir sınıflama modeli geliştirmişlerdir. Farelerde yaptıkları S.aureus osteomiyelit modelinde (femur osteotomi ve plak-vida tespiti zemininde) normal parametreler yanında 1) kallus-korteks oranı, 2) kaynamanın miktarı, 3) kemik iliği değişiklikleri ve 4) bakteri sayısı (100 büyütmede 20 sahada dört ve üzeri bakteri varlığı) kriterlerini eklemişlerdir. ${ }^{[22]}$

Bottagisio ve ark., tavşan osteomiyelit modellerini inceledikleri derlemelerinde 2008 ile 2018 arası çıkan yayınları incelemişlerdir. Toplam 708 çalışmanın sadece 115 tanesini değerlendirmeye uygun bulmuşlardır. Tavşan modelinin fare ve sıçan modelleri kadar değerli çalışmalar olduğunu, kemik dansitometresi açısından insana en yakın model olduğu, deneylerde halen \%35 oranda tavşan modeli kullanıldığını, en çok tibia, femur ve radiusun kullanıldığını, implant ilişkili kırık modellerinde plak-vida modelinin tercih edildiğini (IM çividen daha çok) saptamışlardır. Ama tavşanların anestezik ajanlara ve antibiyotiklere olan hassasiyeti sıçanlara kıyasla daha fazla olduğunu belirtmişlerdir. ${ }^{[23]}$

\section{OSTEOMIYELIT PATOGENEZININ KANTITATIF ÖLÇÜLERi VE BiYOLÜMINESANS TEKNiĞi}

Yeni aşıların ve antimikrobiyal bileşiklerin; osteomiyelit tedavisindeki etkinliğini doğru bir şekilde değerlendirmek için, enfekte kemik örneklerinde bakteriyel yüklerin nicel olarak ölçülmesine yönelik yöntemlerin geliştirilmesi çok önemlidir. Bakterilerin kemikten izolasyonu zordur, ancak deneysel osteomiyelit modellerindeki son yenilikler hem dolaylı hem de doğrudan önlemler kullanarak bakteriyel yüklerin kesin olarak ölçülmesine izin vermiştir. Hayvan görüntüleme teknolojilerindeki ilerlemeler, enfeksiyon seyri sırasında bakteriyel çoğalmanın kantitatif tayinlerine izin verir. Biyolüminisans görüntüleme, osteomiyelite maruz kalan canlı hayvanlarda patojen yükünü izlemek için başarıyla kullanılmıştır. ${ }^{[20,24-26]}$ Lüminesan sinyal, enfeksiyondan sonra birkaç ay boyunca stabil olarak ölçülebildiğinden, bu invaziv olmayan teknikler deneysel terapötiklerin in vivo etkinliğinin uzun dönem ölçülebilirliği için uygundur. Moleküler görüntüleme, canlı deneklerde moleküler biyolojinin ve hücre biyolojisinin invaziv olmayan görüntülenmesine ve ölçülmesine izin verir. Esas olarak biyolüminisans ve floresan tekniklerini kullanarak yapılan moleküler görüntüleme; osteoblastlar, osteoklastlar ve hormonların aktivitesi, patolojik kıkırdak ve kemik yıkımı mekanizmaları, osteoliz ve osteomiyelitte hücresel süreçleri gösterebilir. ${ }^{[27]}$

Biyolüminisan ışıma, mikroorganizmalar da dahil olmak üzere çeşitli organizmalar tarafından iletişim, üreme ve savunma gibi amaçlar için kullanılır ve hücrelerden görünür ışığın enzimatik üretimi olarak tanımlanır. Fotoaktif proteinlerin biyoloji ve tıpta kullanımı yeşil floresan protein geninin E.coli DNA'sına plazmit aracılığı ile transfer edilmesi ile başlamıştır. Bu araştırma ile 2008 yılında Chalfie, Shimomura ve Tsien Nobel Kimya ödülünü kazanmışlardır. ${ }^{28]}$

İn vivo biyolüminisans görüntüleme, lusiferaz enzimleri ve substratları tarafından üretilen biyolüminisansın görsel temsilini sağlar. Lusiferaz enzimini eksprese eden genetiği değiştirilmiş hücreler veya hayvanlarda biyolüminisan ışıma; enzimin substratı olan lusiferin enjekte edildikten sonra ışıma yapan fotonları elektron yüklerine çeviren hassas kameralar kullanılarak görüntülenebilir (Şekil 1). ${ }^{[29]}$

Ortopedi ve travmatoloji de özellikle osteomiyelit için terapötik müdahaleleri gerçek zamanlı olarak izlemek amaçlı biyolüminisans görüntüleme tekniği kullanılarak uygun in vivo osteomiyelit modellerinin (ve diğer birçok bakteriyel enfeksiyonun) geliştirilmesi için çalışmalar yapılmıştır. Bu çalışmalarda genellikle $S$. Aureus bakteri kromozomu üzerinde Photorhabdus luminescens lux operon'un stabil bir kopyasına sahip suşlar kullanılmıştır (S.aureus -Xen29). ${ }^{[24,30]}$

\section{OSTEOMIYELITTE GÖRÜNTÜLEME TEKNIKLERi}

Enfekte kemikteki patojen yüklerinin miktarının ölçülmesine ek olarak, şimdi osteomiyelitin hayvan modellerinde patojene bağlı kemik yıkımının görüntülenmesi de mümkündür. Mikrobilgisayarlı tomografi 


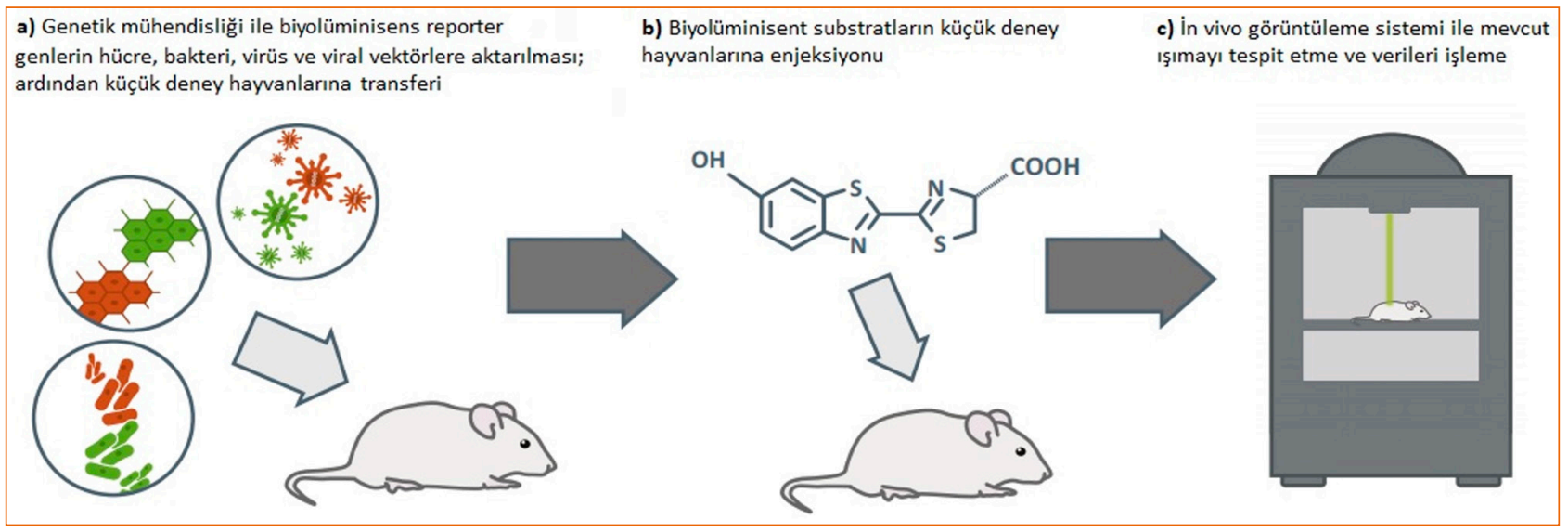

Şekil 1. İn vivo biyolüminisans görüntülemenin şematik yolla anlatılmış üç aşaması. ${ }^{[29]}$

$(\mu \mathrm{CT})$, kemik yoğunluğu ve hacmini hesaplama kabiliyeti nedeniyle kemik biyolojisi alanında sıklıkla kullanılan yüksek çözünürlüklü, üç boyutlu görüntüleme yöntemidir. Bu tür analizler, osteomiyelit sırasında kemik yıkımını yöneten bakteriyel virülans mekanizmalarını incelemek için model sistemler oluşturur. Ek olarak, osteomiyelit sırasında kemiğin yeniden şekillenme sürecini tespit etmek amaçlı yapılan görüntüleme analizleri, osteomiyelitin ana morbiditelerinden birini sınırlamada en etkili olan tedavileri tanımlamak için bir firsat sağlar. Patolojik kemiğin yeniden şekillenmesine karşı koyan ve böylece kemik homeostazı ve vaskülaritesini koruyan yeni terapiler yaratmak, osteomiyelit için geleneksel antibiyotik tedavisinin etkinliği artırılabilir.

\section{BIYYFILM FiZYOLOJiSI VE KRONIK OSTEOMIYELITIN MODELLENMESI}

Antimikrobiyal etkinliği sınırlayan ve osteomiyelit sırasında kronik enfeksiyona neden olan önemli bir faktör biyofilm gelişmesidir. Bu nedenle, osteomiyelitin hayvan modellerinde yeni terapiler veya aşılar test edilirken biyofilm fizyolojisinin in vivo olarak etkili bir şekilde modellenmesi önemlidir. Biyofilm gelişmesi sırasında eksprese edilen bakteriyel antijenleri araştırmak ve biyofilm ile ilişkili enfeksiyona konakçı bağışıklık tepkilerini karakterize etmek için osteomiyelit modelleri geliştirilmiştir. ${ }^{[31-33]}$ Bu modeller, in vivo biyofilm oluşumuna ve terapötik dirence katkıda bulunan unsurların tanımlanmasında önemli bir faydaya sahiptir. ${ }^{[34]}$ Ayrıca, biyofilm enfeksiyonunun hayvan modelleri, biyofilm enfeksiyonunun tedavi edilmesi için geleneksel polivalan bir aşı oluşturulmasını kolaylaştırır. ${ }^{[35]}$
Küçük koloni varyantları (SCV'ler), kronik osteomiyelitten sıklıkla izole edilen yavaş büyüyen, solunum bozukluğu olan bakterilerdir. ${ }^{[36]}$ Birçok antimikrobiyal ajanın etkinliği bakteriyel solunuma ve hücre bölünmesine bağlı olduğundan, SCV'ler kendiliğinden antibiyotik tedavisine dirençlidir. Kronik osteomiyelit için tedavilerin etkinliğini uygun şekilde değerlendirmek için, in vivo modeller SCV'leri ve diğer bakteriyel fizyolojik adaptasyonları, ayrıca kemik mimarisini ve vaskülaritesini hesaba katmalıdır. Bu amaçla Horst ve ark., intravenöz enjeksiyondan sonra kronik osteomiyelitin tekrarlanabilir şekilde indüklendiği bir fare modeli geliştirmiştir. Kronik osteomiyelit, sitokin ve bakteriyolojik analizleri karakterize etmek için kemik enflamasyonunun görüntüleme analizleri ve biyomekanik testler kullanılmışlardır. ${ }^{[37]} \mathrm{Bu}$ grup ayrıca kronik osteomiyelit sırasında SCV gelişimi ve fenotip değişimini analiz etmek için benzer bir hematojen enfeksiyon modeli kullanmıştır. ${ }^{[38]}$

\section{OSTEOMIYELIT IÇIN LOKAL TEDAVILERIN GELIŞTIRILMESI VE IN VIVO DEĞERLENDIRILMESi}

Zhou ve ark., S.aureus ile sıçanlarda yaptıkları yabanCı cisim ilişkili osteomiyelit modelinde curcumin (zerdeçal) ile eritromisin tedavilerini ayrı ayrı ve kombine olarak karşılaştırmışlar ve kombine tedavinin başarılı olduğunu saptamışlardır. ${ }^{[39]}$

Kussmann ve ark., plazma ömrü çok uzun olduğu için ayaktan parenteral tedavilerde tercih edilen yeni bir antibiyotik olan dalbavancin'in (yarı sentetik lipoglikopeptid) etkinliğini sıçanlarda, implant ilişkili osteomiyelit modelinde araştırmışlardır. Dalbavancin'in, vankomisin tedavisi verilen gruplarda elde edilen başarı ile aynı oranda etkili bir monoterapi olabileceğini saptamışlardır. ${ }^{[40]}$ 
Bir diğer araştırma konusu ise bakterinin implanta tutunmasını azaltmak ve enfeksiyona bağlı kemik kaybının restorasyonu için implantlar üzerinde yeni kaplamalar yapılmasıdır. Lovati ve ark., E vitamini ile kaplı titanyum tel yerleştirdikleri sıçan femurlarında kaplamanın S.aureus osteomiyeliti üzerine etkisini araştırmışlardır. Bu çalışmada biyolüminisans görüntüleme ile sonuçları değerledirmişlerdir. E vitaminine bağlı antimikrobiyal etkinin az ama implant kemik ilişkisinin iyi olduğunu saptamışlarıdır. ${ }^{[41]}$

Çalışmalarda yeni hedeflerden birisi enfeksiyonun kemik dokuda verdiği hasarın ne derecede olduğu ve tedavi sonucunda ne derecede iyileştiğidir. Guelcher ve ark., bu hasarı engellemek için enfekte sıçan femur kırı̆̆ı modelinde fizyolojik dozun üzerinde BMP 2 yüklenmiş poliüretan ve kollajen taşıyıcılar ile tedavi uygulamışlar ve greft olarak çok etkili olan bu molekülün enfekte ortamlarda düzenli bir salınım ile sabit bir etkisi olup olmadığını tam olarak ortaya koyamamışlardır.

İmmunoterapinin osteomiyelit olgularında etkisini araştıran çalışmalardan birisi Yokogawa ve ark.'nın farelerde plak-vida uyguladıkları enfekte femur kırığı deneyidir. Bu deney iki açıdan yenilik içermektedir. Birincisi, enfekte zeminde plak vida uygulanan deneklerde ameliyat sonrası 7. gün plak-vida çıkartılarak debridmanı takiben tekrar steril plak-vida konarak tek aşamalı implant revizyonunun yapıldığı ilk deneysel modelidir. Diğer yenilik, böyle enfekte ortamlarda patojen etken olan glikozaminidazın (otolizin molekülünün alt ünitesi) bloke edilmesi ile yani anti-glukozaminidaz monoklonal antikorları (anti-GMD) tedavisi ile kombine edilen vankomisinin etkinliğinin araştırılmasıdır ve immunoterapi yapılan deneklerde enfeksiyon tam olarak tedavi edilmiştir. ${ }^{[42]}$

Biyofilm tabakasını yok edebilmek için moleküler düzeyde yapılan çalışmalardan ilginç olan bir tanesi de Ahn ve ark.'nın lipoteikoik asit in tedavi edici etkisini araştırdıkları çalışmalarıdır. Çünkü teikoik asit esasen biyofilmin ana maddesi olarak bilinir. Farelerin sırtına yerleştirilen enfekte katater modelinde, laktobasil plantarum'dan elde edilen lipoteikoik asitin S.aureus biyofilm tabakasını parçaladığı gösterilmiştir. ${ }^{[43]}$

Antibiyotik taşıyıcı sistem olarak yeni materyaller denenmiş ve Neyisci ile ark., vankomisin (VK) yüklü VK100 silikon sement uygulamasının etkisini sıçan tibiasında yaptıkları implant ilişkili S.aureus osteomiyelit modelinde araştırmışlardır. Sistemik vankomisin ve lokal taşıyıcı sistem uygulaması arasında istatistiksel bir fark saptanmamıştır. ${ }^{[44]}$

Gamaletsou ve ark., tavşanda C.albicans osteomiyelitini mikrobiyolojik, antijenik, histolojik ve florodeoksiglukoz - pozitron emisyon tomografisi - bilgisayarlı tomografi (FDG-PET-BT) çalışmalarını yaparak tanımlamışlardır. Norden'in tibia osteomiyelit modelinin modifıye edilmiş halini kullanarak iki tavşanın tibia intramedüller alanına $10^{9}$, dört tavşanın tibia intramedüller alanına $10^{7}$ dört tavşanın tibia intramedüller alanına $10^{6} \mathrm{CFU} / \mathrm{mL}$ C.albicans inoküle etmişlerdir. $10^{9} \mathrm{CFU} / \mathrm{mL}$ C.albicans inoküle edilen iki tavşan Candida sepsisinden ölmüştür. Ancak $10^{7}$ ve $10^{6} \mathrm{CFU} /$ $\mathrm{mL}$ C.albicans inoküle edilen sekiz tavşandan yedisinde osteomiyelit gösterilmiştir. ${ }^{[13,45]}$

Harrasser ve ark., Wistar Albino ratların proksimal tibia metafizine açlan delikten $10^{2}$ ve $10^{3} \mathrm{CFU} / 10 \mu \mathrm{L}$ S.aureus inoküle ederek hidroksiapatit kaplama titanyum vida veya hidroksiapatit-gümüş kaplama titaniyum vida ile bu deliği kapatarak implant ile ilişkili osteomiyelit modelini oluşturmuşlardır. Bu çalışma sonunda varılan nokta $10^{2}$ veya $10^{3} \mathrm{CFU} / 10 \mu \mathrm{L}$ inokülasyonun aslında osteomiyelit için yeterli olduğu ve daha yüksek dozdaki inokülasyonlara göre klinik manifestasyonları daha güçlü temsil ettiği yönündedir. ${ }^{[46]}$

Avdeeva ve ark., iki grup 20 adet Wistar Albino rat ile yaptıkları deneyde osteomiyelit grubuna düşük virulanslı S.aureus suşları ile üç günlük intervaller ile üç doz intraperitoneal enjeksiyon yaparak pre-sensitizasyon yapmışlardır. Ardından steril ortamda femur distaline ulaşılarak iğne ucu ile medullaya S.aureus inokule etmişler ve takiplerinde sintigrafi, enfeksiyonun klinik ve laboratuvar parametreleri ve histolojik değerlendirme ile yapılmıştır. Deney hayvanları için mortalite ve morbidite düşünüldüğünde, sensitizasyon yapılmadan inokülasyon yapmanın osteomiyelite her zaman neden olmadığı ve bu nedenle tekrarlayan enjeksiyonlar yapmak gerektiğinden bahsedilmiştir. ${ }^{[47]}$

\section{SONUÇLAR VE GELECEĞE PROJEKSIYONLAR}

Hayvan osteomiyelit modellerindeki yeni ilerlemeler, osteomiyelit sırasında konakçı-patojen arayüzünün analizini kolaylaştırmıştır. Bakteriyel yüklerin tam olarak ölçülmesi ve kemik yeniden şekillenmesindeki değişiklikler için yeni araçlar, osteomiyelit patogenezi için kritik olan bakteriyel faktörlerin belirlenmesine yardımcı olmuştur. Kemik destrüksiyonu ve intraosseöz sağkalım için bakteriyel mekanizmaları hedefleyen yeni tedavilerin geliştirilmesi, geleneksel antimikrobiyal tedavi etkinliğini artıracak ve osteomiyelitin morbiditesini azaltacaktır. Sürekli lokal ilaç salınımı için biyolojik olarak bozunabilir iskeleler, deneysel kemik enfeksiyonu modellerinde umut vaat etmektedir. Son olarak, kronik osteomiyelit ve biyofilm gelişmesine karşı bağışıklık yanıtlarının modellenmesi, kemik enfeksiyonlarını önlemek için aşıların geliştirilmesini kolaylaştıracaktır. 


\section{KAYNAKLAR}

1. Reizner W, Hunter JG, O'Malley NT, Southgate RD, Schwarz EM, Kates SL. A systematic review of animal models for Staphylococcus aureus osteomyelitis. Eur Cell Mater 2014;27:196-212. Crossref

2. Williams DL, Haymond BS, Woodbury KL, Beck JP, Moore DE, Epperson RT, Bloebaum RD. Experimental model of biofilm implant-related osteomyelitis to test combination biomaterials using biofilms as initial inocula. J Biomed Mater Res A 2012;100(7):1888-900. Crossref

3. Ziegler P, Boettcher S, Takizawa H, Manz MG, Brümmendorf $\mathrm{TH}$. LPS-stimulated human bone marrow stroma cells support myeloid cell development and progenitor cell maintenance. Ann Hematol 2016;95(2):173-8. Crossref

4. Kolb-Mäurer A, Weissinger F, Kurzai O, Mäurer M, Wilhelm $\mathrm{M}$, Goebel W. Bacterial infection of human hematopoietic stem cells induces monocytic differentiation. FEMS Immunol Med Microbiol 2004;40(2):147-53. Crossref

5. Kahle N, Brenner-Weiss G, Overhage J, Obst U, Hänsch G. Bacterial quorum sensing molecule induces chemotaxis of human neutrophils via induction of p38 and leukocyte specific protein 1(LSP1). Immunobiology 2013;218(2):14551. Crossref

6. Holban A-M, Bleotu C, Chifiriuc MC, Bezirtzoglou E, Lazar $V$. Role of Pseudomonas aeruginosa quorum sensing (QS) molecules on the viability and cytokine profile of human mesenchymal stem cells. Virulence 2014;5(2):303-10. Crossref

7. Thurlow LR, Hanke ML, Fritz T, Angle A, Aldrich A, Williams $\mathrm{SH}$, Engebretsen IL, Bayles KW, Horswill AR, Kielian T. Staphylococcus aureus biofilms prevent macrophage phagocytosis and attenuate inflammation in vivo. J Immunol 2011;186(11):6585-96. Crossref

8. Zaatreh S, Wegner K, Strauß M, Pasold J, Mittelmeier W, Podbielski A, Kreikemeyer B, Bader R. Co-culture of S.epidermidis and human osteoblasts on implant surfaces: an advanced in vitro model for implant-associated infections. PLoS One 2016;11(3):e0151534. Crossref

9. Raic A, Riedel S, Kemmling E, Bieback K, Overhage J, LeeThedieck C. Biomimetic 3D in vitro model of biofilm triggered osteomyelitis for investigating hematopoiesis during bone marrow infections. Acta Biomater 2018;73:250-62. Crossref

10. Tuchscherr L, Kreis C, Hoerr V, Flint L, Hachmeister M, Geraci J, Bremer-Streck S, Kiehntopf M, Medina E, Kribus M, Raschke M, Pletz M, Peters G, Löffler B. Staphylococcus aureus develops increased resistance to antibiotics by forming dynamic small colony variants during chronic osteomyelitis. J Antimicrob Chemother 2016;71(2):438-48. Crossref

11. Junka A, Szymczyk P, Ziółkowski G, Karuga-Kuzniewska E, Smutnicka D, Bil-Lula I, Bartoszewicz M, Mahabady $S$, Sedghizadeh PP. Bad to the bone: on in vitro and ex vivo microbial biofilm ability to directly destroy colonized bone surfaces without participation of host immunity or osteoclastogenesis. PloS One 2017;12(1):e0169565. Crossref

12. Mader JT. Animal models of osteomyelitis. Am J Med 1985;78(6B):213-7. Crossref

13. Norden CW, Kennedy E. Experimental osteomyelitis. I. A description of the model. J Infect Dis 1970;122(5):410-8. Crossref

14. Andriole VT, Nagel DA, Southwick WO. A paradigm for human chronic osteomyelitis. J Bone Joint Surg Am 1973;55(7):1511-5. Crossref
15. Zak O, Zak F, Rich R, Tosch W, Kradolfer F, Scheld WM. Experimental staphylococcal osteomyelitis in rats: therapy with rifampin and cloxacillin alone or in combination. In: Periti P, Grassi GG, editors. Current Chemotherapy and Immunotherapy. Washington, DC: American Society for Microbiology; 1982. p. 973-4.

16. Rissing JP, Buxton T, Weinstein RS, Shockley RK. Model of experimental chronic osteomyelitis in rats. Infect Immun 1985;47(3):581-6. Crossref

17. Gracia E, Lacleriga A, Monzon M, Leiva J, Oteiza C, Amorena B. Application of a Rat Osteomyelitis Model to Comparein Vivoandin Vitrothe Antibiotic Efficacy against Bacteria with High Capacity to Form Biofilms. J Surg Res 1998;79(2):14653. Crossref

18. Ferguson K, Lambe Jr D, Keplinger J, Kalbfleisch J. Comparison of the pathogenicity of three species of coagulase-negative Staphylococcus in a mouse model with and without a foreign body. Can J Microbiol 1991;37(9):722-4. Crossref

19. Fitzgerald Jr RH. Experimental osteomyelitis: description of a canine model and the role of depot administration of antibiotics in the prevention and treatment of sepsis. J Bone Joint Surg Am 1983;65(3):371-80. Crossref

20. Li D, Gromov K, Søballe K, Puzas JE, O'Keefe RJ, Awad H, Drissi H, Schwarz EM. Quantitative mouse model of implantassociated osteomyelitis and the kinetics of microbial growth, osteolysis, and humoral immunity. J Orthop Res 2008;26(1):96-105. Crossref

21. Brinkman CL, Schmidt-Malan SM, Karau MJ, Patel R. A novel rat model of foreign body osteomyelitis for evaluation of antimicrobial efficacy. J Exp Appl Anim Sci 2019;3(1):7. Crossref

22. Büren $C$, Hambüchen $M$, Windolf $J$, Lögters $T$, Windolf CD. Histological score for degrees of severity in an implantassociated infection model in mice. Arch Orthop Trauma Surg 2019;139(9):1235-44. Crossref

23. Bottagisio M, Coman C, Lovati AB. Animal models of orthopaedic infections. A review of rabbit models used to induce long bone bacterial infections. J Med Microbiol 2019;68(4):506-37. Crossref

24. Funao H, Ishii K, Nagai S, Sasaki A, Hoshikawa T, Aizawa M, Okada Y, Chiba K, Koyasu S, Toyama Y, Matsumoto M. Establishment of a real-time, quantitative, and reproducible mouse model of Staphylococcus osteomyelitis using bioluminescence imaging. Infect Immun 2012;80(2):733-41. Crossref

25. Niska JA, Meganck JA, Pribaz JR, Shahbazian JH, Lim E, Zhang N, Rice BW, Akin A, Ramos RI, Bernthal NM, Francis KP, Miller LS. Monitoring bacterial burden, inflammation and bone damage longitudinally using optical and $\mu C T$ imaging in an orthopaedic implant infection in mice. PloS One 2012;7(10):e47397. Crossref

26. Pribaz JR, Bernthal NM, Billi F, Cho JS, Ramos RI, Guo $Y$, Cheung AL, Francis KP, Miller LS. Mouse model of chronic post-arthroplasty infection: Noninvasive in vivo bioluminescence imaging to monitor bacterial burden for long-term study. J Orthop Res 2012;30(3):335-40. Crossref

27. Reumann MK, Weiser MC, Mayer-Kuckuk P. Musculoskeletal molecular imaging: a comprehensive overview. Trends Biotechnol 2010;28(2):93-101. Crossref

28. Avci P, Karimi M, Sadasivam M, Antunes-Melo WC, Carrasco E, Hamblin MR. In-vivo monitoring of infectious diseases in living animals using bioluminescence imaging. Virulence 2018;9(1):28-63. Crossref 
29. Mezzanotte L, van 't Root M, Karatas H, Goun EA, Löwik CWGM. In vivo molecular bioluminescence imaging: new tools and applications. Trends Biotechnol 2017;35(7):64052. Crossref

30. Hardy J, Chu P, Contag CH. Foci of Listeria monocytogenes persist in the bone marrow. Dis Model Mech 2009;2(12):39-46. Crossref

31. Brady RA, Leid JG, Camper AK, Costerton JW, Shirtliff ME. Identification of Staphylococcus aureus proteins recognized by the antibody-mediated immune response to a biofilm infection. Infect Immun 2006;74(6):3415-26. Crossref

32. Prabhakara R, Harro JM, Leid JG, Harris M, Shirtliff ME. Murine immune response to a chronic Staphylococcus aureus biofilm infection. Infect Immun 2011;79(4):1789-96. Crossref

33. Beenken KE, Dunman PM, McAleese F, Macapagal D, Murphy E, Projan SJ, Blevins JS, Smeltzer MS. Global gene expression in Staphylococcus aureus biofilms. J Bacteriol 2004;186(14):4665-84. Crossref

34. Weiss EC, Zielinska A, Beenken KE, Spencer HJ, Daily SJ, Smeltzer MS. Impact of sarA on daptomycin susceptibility of Staphylococcus aureus biofilms in vivo. Antimicrob Agents Chemother 2009;53(10):4096-102. Crossref

35. Brady RA, Graeme A, Leid JG, Prior ML, Costerton JW, Shirtliff ME. Resolution of Staphylococcus aureus biofilm infection using vaccination and antibiotic treatment. Infect Immun 2011;79(4):1797-803. Crossref

36. Proctor RA, Von Eiff C, Kahl BC, Becker K, McNamara P, Herrmann M, Peters G. Small colony variants: a pathogenic form of bacteria that facilitates persistent and recurrent infections. Nat Rev Microbiol 2006;4(4):295-305. Crossref

37. Horst SA, Hoerr V, Beineke A, Kreis C, Tuchscherr L, Kalinka J, Lehne S, Schleicher I, Köhler G, Fuchs T, Raschke MJ, Rohde M, Peters G, Faber C, Löffler B, Medina E. A novel mouse model of Staphylococcus aureus chronic osteomyelitis that closely mimics the human infection: an integrated view of disease pathogenesis. Am J Pathol 2012;181(4):1206-14. Crossref

38. Tuchscherr L, Medina E, Hussain M, Völker W, Heitmann V, Niemann S, Holzinger D, Roth J, Proctor RA, Becker K, Peters G, Löffler B. Staphylococcus aureus phenotype switching: an effective bacterial strategy to escape host immune response and establish a chronic infection. EMBO Mol Med 2011;3(3):129-41. Crossref
39. Zhou Z, Pan C, Lu Y, Gao Y, Liu W, Yin P, Yu X. Combination of erythromycin and curcumin alleviates Staphylococcus aureus induced osteomyelitis in rats. Front Cell Infect Microbiol 2017;7:379. Crossref

40. Kussmann M, Obermueller M, Berndl F, Reischer V, Veletzky L, Burgmann H, Poeppl W. Dalbavancin for treatment of implant-related methicillin-resistant Staphylococcus aureus osteomyelitis in an experimental rat model. Sci Rep 2018;8(1):9661. Crossref

41. Lovati $A B$, Bottagisio M, Maraldi S, Violatto MB, Bortolin $M$, Vecchi ED, Bigini P, Drago L, Romanò CL. Vitamin E phosphate coating stimulates bone deposition in implantrelated infections in a rat model. Clin Orthop Relat Res 2018;476(6):1324. Crossref

42. Yokogawa $N$, Ishikawa $M$, Nishitani $K$, Beck CA, Tsuchiya $H$, Mesfin A, Kates SL, Daiss JL, Xie C, Schwarz EM. Immunotherapy synergizes with debridement and antibiotic therapy in a murine 1-stage exchange model of MRSA implantassociated osteomyelitis. J Orthop Res 2018;36(6):1590-8. Crossref

43. Ahn KB, Baik JE, Yun C-H, Han SH. Lipoteichoic acid inhibits Staphylococcus aureus biofilm formation. Front Microbiol 2018;9:327. Crossref

44. Neyisci C, Erdem Y, Bilekli AB, Demiralp B, Kose O, Bek D, Korkusuz F, Kankilic B. Treatment of implant-related methicillin-resistant Staphylococcus aureus osteomyelitis with vancomycin-loaded VK100 silicone cement: An experimental study in rats. J Orthop Surg 2018;26(1):2309499017754093. Crossref

45. Gamaletsou MN, Meletiadis J, Chatziioannou S, Panayiotides IG, Agadakos E, Katsimpoulas M, Kostomitsopoulos N, Petraitis V, Walsh TJ, Sipsas NV. Experimental Candida albicans osteomyelitis: Microbiologic, antigenic, histologic, and 18FDG-PET-CT imaging characteristics in a newly established rabbit model. Med Mycol 2019;57(8):1011-7. Crossref

46. Harrasser N, Gorkotte J, Obermeier A, Feihl S, Straub M, Slotta-Huspenina J, von Eisenhart-Rothe R, Moser W, Gruner $\mathrm{P}$, de Wild M, Gollwitzer H, Burgkart R. A new model of implant-related osteomyelitis in the metaphysis of rat tibiae. BMC Musculoskelet Disord 2016;17(1):152. Crossref

47. Avdeeva EY, Slizovsky G, Skorokhodova M, Fomina TI, Zorkaltsev MA, Zavadovskaya VD, Krasnov EA, Ivanov W, Stepanov MY. Experimental simulation of traumatic osteomyelitis in rats. Bull Exp Biol Med 2016;161(1):137-40. Crossref 